\title{
Museos: entre identidades cristalizadas y mercados transnacionales*
}

\author{
Rubens Bayardo \\ Programa Antropología de la Cultura, \\ Facultad de Filosofia y Letras, \\ Universidad de Buenos Aires.
}

RESUMEN: En este trabajo abordamos, en primer lugar, la problemática de las nuevas coordenadas que implica la transnacionalización y el lugar que ocupa la cultura en este proceso. Seguidamente, caracterizamos los recientes desarrollos del sector cultural en Argentina y los cambios acaecidos en la institución museo, considerando la constitución del patrimonio con relación a las políticas culturales y a la gestión cultural. Luego, nos centramos en el caso del Museo de Arte Popular José Hernández y analizamos una actividad en particular, la Exposición y Feria Artesanal Cultural de los Pueblos Originarios. Ésta forma parte de un programa de valorización de las artesanías y de los mismos artesanos indígenas, cuyo desarrollo deja a la vista los conflictos por la definición y la apropiación del patrimonio, y por la visibilidad y el reconocimiento dignificantes de las identidades sociales de sus productores en el marco de la transnacionalización. Ello nos permite abordar las dificultades que se plantean para el cumplimiento de los objetivos propuestos por el museo, cuando la renovación de la institución y de sus prácticas gestionarias no están acompañadas por políticas culturales públicas transversales, que las encaucen y potencien en los sentidos buscados.

PALABRAS ClAVE: Museos. Transnacionalización. Patrimonio. Identidades. Gestión cultural. Políticas culturales.

RESUMO: Neste trabalho abordamos, em primeiro lugar, a problemática das novas coordenadas que a transnacionalização implica e o lugar que ocupa a cultura nesse processo. A seguir, caracterizamos o recente desenvolvimento do setor cultural na Argentina e as mudanças ocorridas na instituição museu, considerando a constituição do patrimônio em relação às políticas culturais e à gestão cultural. Centramo-nos então no caso do Museo de Arte Popular José Hernández e analisamos uma atividade em particular, a Exposición y Feria Artesanal Cultural de los Pueblos Originarios. Essa exposição faz parte de um programa de valorização do artesanato e dos artesãos indígenas, cujo desenvolvimento torna visíveis os conflitos pela

\footnotetext{
* Versão final de texto apresentado na IV Semana dos Museus - Preservação em Museus: identidades, políticas, memórias, agosto de 2003, Universidade de São Paulo, São Paulo.
} 
definição e apropriação do patrimônio e pela visibilidade e reconhecimento dignos das identidades sociais dos seus produtores no contexto da transnacionalização. Isso permite abordar as dificuldades que ocorrem para atingir os objetivos propostos pelo museu, quando a renovação da instituição e de suas práticas de gestão não são acompanhadas por políticas culturais públicas transversais, que encaminhem e potencializem o trabalho nas direções procuradas.

PALAVRAS-ChaVE: Museus. Transnacionalização. Patrimônio. Identidades. Gestão cultural. Políticas culturais.

ABSTRACT: This article approaches, firstly, the problematic of the new coordinates implied in transnationalisation, and the place occupied by culture in this process. Then, the recent development of the Argentinean cultural sector and the changes undergone by the museum institution are characterised, considering patrimony constitution with regards to cultural policies and cultural management. The focus is then cast on the case of the Museo de Arte Popular José Hernández, and a specific activity is analysed, that of the Exposición y Feria Artesanal Cultural de los Pueblos Originarios. This exhibition is part of a programme of indigenous handcraft and artisans valorisation, which development makes evident the conflicts for the definition and appropriation of patrimony, and for the visibility and dignified recognition of the social identity of its producers within the context of transnationalisation. This allows for the study of the difficulties experienced in the fulfilling of the aims proposed by the museum, when the renovation of the institution and of its management practices are not accompanied by transversal public cultural policies, which would guide and potentialise the work in the intended directions.

KEYWORDS: Museums. Transnationalisation. Cultural Heritage. Identities. Cultural Management. Cultural Policies.

Aunque la presencia de artesanos en la acera no viole ninguna norma, atenta contra la estética de la Avenida del Libertador

(intervención de un abogado)

En los últimos tiempos con los procesos de transnacionalización hemos asistido a transformaciones drásticas en las relaciones entre economía, política y cultura. Este último dominio, que décadas atrás podía ser conceptualizado como de relativa autonomía respecto de las relaciones sociales más generales, en la actualidad se perfila como un espacio no sólo no externo, sino de pregonada centralidad en las estrategias de desarrollo democrático. La cultura y la identidad son visualizadas por gobiernos, agencias internacionales y entidades de financiamiento como un recurso, en ocasiones privilegiado, en la generación de riqueza y de empleo, en la inclusión social y en la recualificación del tejido urbano, en la participación y el afianzamiento de prácticas democráticas. En el caso de la Argentina, los museos usualmente han sido vistos al modo de verdaderos 
templos laicos del orden y las identidades cristalizadas de la era de las naciones. Hoy en día, como parte de los procesos mencionados, se espera de ellos transformaciones de índole gestionaria que mejoren su administración, amplíen sus públicos, aseguren su financiamiento y su contribución a la vida económica, lo que no deja de plantear complicaciones. A la vez, la preservación, la curaduría, la exhibición, etc. se vuelven parte de renovadas disputas políticas, al evidenciarse su importancia en el reconocimiento, la visibilidad y la representación dignificante de las diversas identidades sociales y de la ciudadanía en el contexto del mercado transnacional, siendo este otro marco de conflicto.

En este trabajo abordamos en primer lugar la problemática de las nuevas coordenadas que implica la transnacionalización y el lugar que ocupa la cultura en este proceso. Seguidamente caracterizamos los recientes desarrollos del sector cultural en Argentina y los cambios acaecidos en la institución museo, considerando la constitución del patrimonio con relación a las políticas culturales y a la gestión cultural. Luego nos centramos en el caso del Museo de Arte Popular José Hernández y analizamos una actividad en particular, la Exposición y Feria Artesanal Cultural de los Pueblos Originarios. Ésta forma parte de un programa de valorización de las artesanías y de los mismos artesanos indígenas, cuyo desarrollo deja a la vista los conflictos por la definición y la apropiación del patrimonio, y por la visibilidad y el reconocimiento dignificantes de las identidades sociales de sus productores en el marco de la transnacionalización. Ello nos permite abordar las dificultades que se plantean para el cumplimiento de los objetivos propuestos por el museo, cuando la renovación de la institución y de sus prácticas gestionarias no están acompañadas por políticas culturales públicas transversales que las encaucen y potencien en los sentidos buscados.

Transnacionalización y cultura

En la década de los noventa asistimos a la expansión de diversos discursos sobre la globalización, los que lograron concentrar las atenciones y los intentos de explicación de nuevos procesos que se vivían desde los años 70' (BAYARDO; LACARRIEU, 1997, 1999). Aunque los debates arrojaron renovadas luces sobre fenómenos conocidos y sobre otros más recientes, no todo lo que el término "globalización" refería era nuevo. Pero lo más llamativamente novedoso es que una noción nacida en el mundo empresarial y cargada de ideología, irrumpiera con tanta aceptación y popularidad, explicando esos procesos como un fenómeno natural e inevitable, al que subirse con unas pocas recetas'. En tal sentido, entendemos que la menos extendida noción de transnacionalización, refiere de modo menos equívoco y más complejo al atravesamiento (ORTIZ, 1996) de los Estados nacionales por flujos de finanzas, de tecnologías, de personas, de medias y de ideas, no isomórficos ni simétricos (APPADURAI, 1994), cuyos efectos en los países latinoamericanos han sido una mayor distribución desigual del ingreso, la pauperización y el incremento de la brecha social, el
1. Nos referimos a consignas como "pensar global, actuar local", "glocalice" etc. Véase SONNTAG; ARENAS, 1995. 
2. Los teóricos de la regulación (Anglietta, Boyer, Liepietz, Hirsch, entre otros) conciben a las formas históricas del capitalismo como basadas en la interrelación compleja entre un régimen de acumulación y un modo de regulación. El régimen de acumulación refiere "al modo de distribución sistemática y de locación real del producto social, que provoca a través de un período largo una cier ta relación entre cambios en las condiciones de producción (el volumen del capital invertido, la distribución entre ramas y niveles de producción) y cambios en las condiciones del consumo (normas de consumo de los trabajadores y otras clases sociales, gastos colectivos etc.)", mientras que el modo de regulación define "la totalidad de formas, redes y normas institucionalizadas, implícitas y explícitas, las cuales aseguran la compatibilidad de actitudes dentro de un régimen de acumulación, tanto en lo que corresponde a las condiciones de la sociedad,como en lo que rebasa sus características conflictivas" (Liepietz citado en HIRSCH, 1995, p 120-121).

3.Gentili (1998,p. 126) especifica que "el programa de ajuste y estabilización propuesto en el marco de ese 'consenso' incluye diez tipos específicos de reforma que, tal como señala Williamson, han sido implementados casi siempre con intensidad por los gobiernos latinoamericanos a partir de la década del 80: disciplina fiscal, redefinición de las prioridades del gasto público, reforma tributaria, liberalización del sector financiero, mantenimiento de tasas de cambio competitivas, liberalización comercial, atracción de inversiones de capital extranjero, pri- crecimiento de la delincuencia, la protesta social y la violencia (CANCLINI, 1999).

Orientados por los teóricos de la regulación ${ }^{2}$ pensamos que la expansión de mercados globales, a partir de la crisis de acumulación capitalista bajo moldes nacionales, es expresión del pasaje del régimen de acumulación fordista al postfordista. Este último se caracteriza por la dispersión geográfica y la especialización flexible de la producción, la importancia creciente del sector de los servicios y del conocimiento, la disminución de la importancia y del tamaño de las industrias, la subcontratación y la flexibilización de las condiciones del trabajo, la prefiguración del consumo en la producción, y con ella la estetización y la culturización de bienes y servicios. Por su parte, con esa misma perspectiva teórica, la revaluación privada del capital y la transferencia de costos a la sociedad, unidos a la desregulación y al achicamiento de la política, expresan el tránsito del modo de regulación del Estado de bienestar keynesiano al Estado neoliberal (HARVEY, 1995, p. 172 y ss.). Desde el denominado Consenso de Washington ${ }^{3}$ se postula la necesidad de un aparato estatal pequeño y limitado en sus competencias, sólo obligado a garantizar la seguridad jurídica de empresas, capitales, inversores y propietarios. La dinamización de los mercados internos, la distribución de los ingresos en pro de la ampliación de la base del consumo, y la provisión de servicios públicos en salud, educación, cultura, son considerados un desborde estatista y una intromisión de la política sobre lo que se visualiza como cuestiones de índole privada, mejor equilibradas por la "mano invisible" del mercado.

En ese esquema, los "costos sociales" y las "fallas del mercado" no resueltos por el Estado ni por la iniciativa privada, se espera que sean paliados por el esfuerzo de la sociedad misma, concebida como un "tercer sector", privado pero con intereses públicos, también denominado "sector social", "sector asociativo", "sector intermedio", "sociedad civil" o simplemente "comunidad". Con ello cierra un círculo perfecto, donde la caducidad de los derechos económicos, sociales y culturales - por obra de un Estado al servicio del mercado, y de un mercado al servicio de sí mismo -, encontraría remedio por la vía del voluntariado, la solidaridad y las prácticas integradoras de la sociedad civil. Este renovado contrato social entre el Estado, el mercado y la comunidad reposa no sólo sobre el nuevo lugar que la cultura tiene en la producción como factor económico. También lo hace sobre el achicamiento y la despolitización de la política, que a la vez potencian el lugar de la cultura como mediadora simbólica, como argamasa y elemento de inclusión social, como factor de pertenencia y de consenso (SOSNOWSKI, 1999).

En tal sentido, la importancia en la vida contemporánea de la cultura y de las identidades, se debe, más que al reconocimiento de sus valores intrínsecos, a su valor instrumental como "recurso" económico y político (YUDICE, 2002), lo que sin duda incide sobre esos aspectos intrínsecos. En los años setenta la industrialización de la protección del medio ambiente dio lugar a un ecocapitalismo, donde los sectores involucrados en esta nueva rama del desarrollo se beneficiaron y aumentaron la concentración del capital ${ }^{4}$. En la configuración 
actual nos parece pertinente referirnos a un cultural-capitalismo, que instala la cuestión de la cultura en el centro del desarrollo y motoriza la dinámica del sector, con vistas a su más completa inclusión en la lógica del valor de cambio. Quizás la cara más fácilmente visible del fenómeno a que nos referimos esté en el turismo cultural, caracterizado por utilizar como insumo mercantil a los individuos, a los grupos, al medio natural en que se desenvuelven y a su propia cultura, tanto en sus manifestaciones tradicionales como en las contemporáneas. Pero este mecanismo se halla generalizado en toda la "industria de la cultura" (GETINO, 1995), que amén del turismo cultural, comprende a las industrias culturales ${ }^{5}$, a las artes y los espectáculos, al diseño y la moda, a la renovación urbana y el redesarrollo local, y por supuesto también al patrimonio tangible e intangible. El auge y la moda de la cultura ponen a este complejo productivo en situación de desarrollar potencialidades ya reconocidas y de alcanzar rentas antes impensables. Con todo, aunque (con diferentes énfasis desde el Estado, el mercado y la comunidad) se esperan del sector imágenes que promocionen la "marca" Argentina, generación de ingresos y riquezas, creación de empleos, exportaciones que mejoren la balanza de pagos, etc., apenas se evidencia la elaboración o la implementación de políticas a largo plazo que aprovechen esta avizorada "ventaja competitiva".

El sector cultural, el patrimonio y los museos

En la Argentina es interesante anotar cómo se perfila desde el Estado en sus distintos niveles nacional, provincial y municipal, la utilización, e inclusive la promoción de la cultura como recurso económico del que se espera rendimiento, algo ostensible en la realización de muestras, ferias, festivales, circuitos turísticos, etc., muchas veces sobre la base de que "la cultura es barata" ${ }^{\text {. Con todo y }}$ simultáneamente, se aprecia el estancamiento de los presupuestos unido a repetidos recortes, que conllevan la reducción de los fondos públicos para la cultura. El financiamiento apenas alcanza para sostener las infraestructuras, costear los servicios elementales y pagar los salarios del personal (por otra parte congelados desde 1989), pero no cubre los gastos operativos de las instituciones culturales. En el caso de los museos resulta visible el deterioro edilicio y de las condiciones de conservación, la falta de profesionales idóneos y la escasez de actividades de capacitación, la ausencia de políticas de adquisición y la desactualización de las colecciones. Esta situación de relativo abandono responde a las políticas de ajuste estructural más generales que, en ausencia de políticas culturales públicas, proponen al sector fórmulas de salvación financiera que remiten a una gestión cultural diríamos autónoma", como "que los monumentos se ganen la vida" o que "la cultura tiene que aprender a hacer lobby" .

Este contexto carga a cada institución con el peso del obtener fuentes alternativas de financiamiento y otros apoyos que le permitan funcionar adecuadamente, lo que genera una competencia silenciosa por recursos escasos. vatización de empresas estatales, desregulación de la economía, protección de derechos de autor".

4. Véase ENZENSBERGER, 1974, p. 32 y ss.

5. Las industrias culturales son un vasto conglomerado de procesos productivos y de comercialización basados en la creación y reproducción serializada de bienes y servicios culturales transables en el mercado, los que son objeto de consumos tanto masivos como segmentados. Su núcleo reside en la edición gráfica y discográfica, el cine y el video, la radio, la televisión y la publicidad, las industrias de la información y de la comunicación.

6. Esta aseveración es un lugar común en el discurso de los funcionarios de cultura, destacándose como uno de sus mentores el Secretario de Cultura y Medios de Comunicación de la Nación de los años 2000 y 2001, Darío Lopérfido.

7. No decimos que la gestión cultural sea efectivamente autónoma, sino que desde las instancias centrales por una parte se reclaman controles, esfuerzos y resultados, mientras que por otra, se libra a las diversas reparticiones a su propia suerte

8. Expresiones del Secretario de Cultura de la Nación, Mario O'Donnel, y del vocal de la Comisión Nacional de Museos, Monumentos y Lugares Históricos, Horacio Burbridge, respectivamente. Véase Diario Clarín, Buenos Aires, 16/12/1996. 
9.Al respecto puede verse Cuicuilco (1996) que reúne interesantes aportes de Felipe Lacouture Fornelli, Graciela Smilchuk y Luis Gerardo Morales Moreno.
Obtener esos medios económicos, les significa a los museos, la posibilidad de mejorar los depósitos, incorporar tecnologías para la conservación, hacer cambios en las muestras permanentes, encarar exhibiciones temporales, etc. Es por ese motivo que muchos se encuentran en un proceso de fuerte renovación gestionaria, que aunque centrado en la recaudación de fondos, no se limita a ella. La proliferación de merchandising e imágenes de marca, las tiendas de regalos, las confiterías y restaurantes, así como el alquiler de instalaciones o la circulación de muestras que proporcionan economías de escala, son parte de este nuevo paisaje. De aquí la conformación de asociaciones de amigos para viabilizar el ingreso de dinero proveniente de ventas, de servicios tercerizados, o de donaciones, y la búsqueda de alianzas con el sector privado por medio de auspicios y patrocinios. De aquí también los intentos de conseguir mejores inserciones en el medio cultural o las comunidades locales y de hacer al museo "amigable" con sus visitantes.

En esas transformaciones no se pueden ignorar los influjos de una nueva museología', que repiensa las funciones del museo, sus vinculaciones con los públicos, las prácticas de selección, preservación, curaduría, y sus relaciones con el guión museográfico. Sin embargo, creemos que la renovación museológica e inclusive la museográfica, es menos significativa que la transformación gestionaria, donde se adoptan o al menos se declaman criterios de eficacia, eficiencia, rentabilidad, orientación al usuario, muchas veces como recetas incuestionadas. A decir verdad también son pocas las posibilidades de ensayar una reflexión crítica o de pergeñar otras modalidades, cuando las presiones del recorte presupuestario ponen en jaque la supervivencia institucional y la continuidad laboral. Paradóiicamente esto ocurre en el mismo momento en que, con el auge y la moda de la cultura, los museos viven su hora de gloria, convertidos al decir de Andreas Huyssen en un "medio de masas", que cambia drásticamente los mecanismos previos de inclusión/exclusión asociados al "templo de las musas" (HUYSSEN, 2002).

Según sostiene Prats, desde del romanticismo, la naturaleza, la historia y la inspiración creativa constituyen los lados de un triángulo donde se pone en juego la dinámica de inclusión y exclusión patrimonial. Pero no se trata de una selección neutra pues

el patrimonio no existe más que cuando, desde determinadas instancias, es activado, es decir, se promueve una determinada versión de una determinada identidad, para lo cual se selecciona, se interpreta y se representan un repertorio de referentes ad-hoc. [...] Sin poder, podríamos decir, no hay activación patrimonial, y por tanto, no hay patrimonio (PRATS, 1997, p. 31.

Queda clara la actuación de los poderes públicos en estas activaciones patrimoniales, pero cabe además señalar el papel de la iniciativa privada en un mismo sentido. Del papel mancomunado de ambos agentes dan cuenta la revitalización de centros históricos, el ennoblecimiento de áreas degradadas y el redesarrollo urbano en torno a sitios de interés patrimonial. Pero no puede descuidarse el papel de la misma sociedad que, en el marco del cultural- 
capitalismo y de la inflación cultural a que nos hemos referido, no sólo no rechaza la "museización", sino que practica una "museomanía" que ha "enterrado el museo como templo de las musas para resucitarlo como espacio híbrido, mitad feria de atracciones, mitad grandes almacenes" (HUYSSEN, 2002, p. 44).

Esta caracterización que da cuenta del reciente influjo de los museos, podría alentar la idea de que un renovado espíritu democratizante, reconocido por antiguos y modernos visitantes, inspira las nuevas prácticas gestionarias y museográficas. Inclusive podría llegar a interpretarse (como reza una difundida vulgata) que es el éxito de la gestión cultural de cada institución particular lo que despierta la adhesión de los públicos, puebla los museos, incrementa sus cifras y realiza desafíos educativos largamente esperados. Por nuestra parte entendemos que estas no son sino verdades a medias, que parecen echar luz sobre los acontecimientos, pero que oscurecen el cauce de sus desarrollos. Más bien nos interesa destacar cómo las políticas culturales ${ }^{10}$, entendidas como políticas públicas transversales y no sólo sectoriales (RIZZARDO, 1995), siguen siendo una cuenta pendiente que difícilmente puedan saldar las mejores prácticas de gestión cultural ${ }^{11}$. Estas últimas no bastan para desarticular la inclusión de identidades cristalizadas en torno a un patrimonio congelado y la exclusión de identidades negadas y hasta expulsadas de la cultura. Y es precisamente la ausencia de esas políticas lo que hace de la democratización una alusión a la apertura del acceso a las infraestructuras edilicias, más que una referencia a la participación efectiva y reconocida de la pluralidad cultural en la institución museo. En los siguientes acápites procuraremos dar cuenta de ello a partir de un caso en particular.

El Museo de Arte Popular José Hernández: disputas em torno al patrimonio y las identidades

El Museo de Arte Popular José Hernández depende de la Secretaría de Cultura del Gobierno de la Ciudad de Buenos Aires, y fue inaugurado en 1948 como un Museo de Motivos Argentinos. Esa denominación tiene que ver con la colección que le dio origen, la que incluye trabajos en plata, en cuero, en telar, en objetos tales como mates, fustas, arreos, mantas, aperos, etc. Este acervo evocaba la vida rural desde la perspectiva idealizada, estereotipada y esteticista que el criollismo ${ }^{12}$ construyó del gaucho ${ }^{13}$ y del campo. De aquí que el museo lleve el nombre de 'José Hernández', autor del reconocido libro Martín Fierro, texto emblemático de la literatura nacional argentina. La actual dirección lleva más de 10 años de gestión, en los que ha puesto en discusión la problemática del patrimonio y de la museología desde una perspectiva semiótica. En esa sintonía ha procurado transformar el guión museográfico, rompiendo con prácticas de exhibición que reproducen estereotipos y perspectivas homogeneizantes de la nación y sus habitantes, para pasar a exponer las diversas situaciones sobre las que se constituye la realidad heterogénea del país.
10. Según Néstor García Canclini $(1987$, p. 26) las políticas culturales son un "conjunto de intervenciones realizadas por el Estado, las instituciones civiles y los grupos comunitarios organizados a fin de orientar el desarrollo simbólico, satisfacer las necesidades culturales de la población, y obtener consenso para un tipo de orden o de transformación social".

11. La gestión cultural es una actividad de mediación entre los diversos actores, cuerpos disciplinares y especialidades puestos en juego en las distintas fases productivas de los procesos culturales, enfocada a la concreción de acciones puntuales, proyectos o programas, pero no siempre ni necesariamente orientada por políticas culturales. Al respecto véase BAYARDO, 2001.

12. Se denomina "criollismo" a la corriente literaria que entre comienzos del siglo XX y 1940, frente al cosmopolitismo de las ciudades en expansión, enarbola la figura del gaucho como un icono de la cultura nacional,proponiendo un grupo limitado de representaciones como si fueran característicos de esa totalidad heterogénea. Mas que de un movimiento antimodernizante se trata de un complejo dispositivo ideológico que afirma la idiosincrasia nacional como forma de incorporación al proceso modernizador.

13. El gaucho es en principio el poblador mestizo de las pampas del Río de la Plata, identificable con el gaucho brasileño, el huaso chileno, el llanero venezolano. Con todo, cabe señalar que el gaucho ha sido objeto de distintas construcciones identitarias. Recreando el mito 
del 'buen salvaje', éstas responden a atribuciones de bonhomía y de saber telúrico de quien vive compenetrado con su medio, aunque por otro lado, éstas se asocian a la barbarie y a la noción del gaucho como matrero y taimado. Al respecto véase JULIANO, 1992, 1994.

14. Ello se liga con la conceptualización semiótica que orienta la gestión.Al respecto véase COUSILLAS, 2001, 2003.
La nueva denominación Museo de Arte Popular procura dar cuenta de ese giro hacia las distintas poblaciones tradicionales e indígenas y sus producciones artesanales. El museo lleva adelante un Programa de Patrimonialización de las Artesanías y Promoción de los Artesanos, con el que se propone no sólo exponer piezas artesanales, sino también demostrar las habilidades de los productores, vincular directamente a los artesanos con los públicos y ofrecerles un canal de comercialización de sus trabajos ${ }^{14}$. En relación con ello existe una activa preocupación por cambiar la imagen del museo entre sus audiencias reales y potenciales, para lo cual se han encarado estudios de público y análisis de la política de comunicación del museo. Los exhibits del José Hernández en algunas estaciones del subterráneo de la ciudad y en diversos eventos culturales, la página web del museo, los boletines informativos también dan cuenta de esta búsqueda.

El Museo de Arte Popular José Hernández se localiza en la zona de Palermo Chico, conocida por sus vecinos como "Barrio Parque". Se trata de una zona de muy alto nivel socio económico, acorde al elevado valor del suelo en el área, que está entre las más costosas de Buenos Aires. En Palermo Chico abundan mansiones, embajadas, concesionarias de automóviles de lujo, confiterías selectas de la ciudad. La presencia de cabinas de vigilancia, choferes, personal de seguridad pública y privada, servicio doméstico uniformado, da cuenta de los sectores privilegiados que viven en el lugar. El museo está ubicado sobre la Avenida del Libertador, eje monumental situado en el norte rico de la ciudad, cercano a la ribera del Río de la Plata. La avenida está circundada de amplios parques en buena parte de su trazado, es lindera con el Zoológico y está próxima al Jardín Botánico, lo que en una ciudad pobre en áreas verdes la convierte en un espacio recreativo muy frecuentado. También se trata de un relevante eje cultural, pues sobre esta arteria, o en sus proximidades, se localizan destacadas infraestructuras culturales. Nos referimos a las Salas Nacionales de Exposición del Palais de Glace, al Centro Municipal de Exposiciones, al Centro Cultural Recoleta, al Museo Nacional de Bellas Artes, a la Biblioteca Nacional, al Museo Nacional de Arte Decorativo, y al Museo de Arte Latinoamericano de Buenos Aires.

Comparado con estas infraestructuras monumentales y/o de grandes superficies, el petit hotel que ocupa el Museo de Arte Popular es relativamente pequeño, y pasa casi inadvertido entre las casonas y edificios de la Avenida del Libertador. Algo similar sucede con el acervo de folk arts de este último, en comparación con las obras que forman parte de las colecciones y muestras de las instituciones mencionadas, todas ellas vinculadas al arte culto y a las expresiones legitimadas. Pero además de esto, si el guión museográfico anterior se emparentaba con las realizaciones y los imaginarios valorados por las elites locales, el actual dista de poner el acento sobre aquellas expresiones con las que estos sectores quieren verse identificados o están dispuestos a reconocer. De aquí que la localización socioespacial del "José Hernández" plantea algunos desafíos para la nueva propuesta museográfica y las nuevas prácticas de visita que el museo ofrece a sus públicos. 
Desde el año 2000 el Museo de Arte Popular viene organizando durante todo el mes de octubre la Exposición y Feria Artesanal Cultural de los Pueblos Originarios. En ella se hacen presentes artesanos de grupos kolla, toba, guaraní, mapuche, etc. los que no sólo exhiben sus mejores obras, sino que también trabajan a la vista de los visitantes, dialogan con éstos y ofrecen a la venta sus productos ${ }^{15}$. Dado que por el régimen administrativo financiero de la ciudad, el museo no puede realizar ventas ni ingresar dinero en sus arcas, éstas se organizan fuera de su órbita, directamente entre productores y compradores, en el ámbito de la referida Feria. El museo procura dar a los artesanos indígenas oportunidades de las que carecen en los lugares donde viven, y a la vez permitirles resarcir los gastos de traslado y estancia en la ciudad, que corren por su propia cuenta ya que la institución carece de fondos para sostenerlos. Pero los esfuerzos por dar lugar a un nuevo paradigma sobre el patrimonio cultural, abren paso al estallido de conflictos entre interpretaciones divergentes del mismo.

La directora del museo, la antropóloga Ana María Cousillas (200 1, p. 214 y ss.), ilustra esta situación con un caso al que sugestivamente llama "artesanos indígenas versus la estética de la Avenida del Libertador". El cierre de la primera Exposición y Feria Artesanal Cultural de los Pueblos Originarios, se produjo los días 27 y 28 de octubre de 2000. Para la ocasión los artesanos trasladaron sus mesas de trabajo y de exposición desde el interior del predio del museo a la vereda del mismo. Algunos vecinos hicieron una denuncia a la comisaría de la zona, ante lo que consideraron una infracción de la ordenanza municipal que prohíbe la venta en la vía pública. Las autoridades del museo debieron explicar al personal policial que no se trataba de una venta callejera, sino de un "evento de promoción del patrimonio cultural autóctono, organizado por el museo con autorización de las autoridades del gobierno de la ciudad". El lunes 29 la institución recibió el llamado de un abogado representante del consorcio de un edificio vecino, quienes el domingo anterior, "preocupados por la ocupación de la acera", realizaron una reunión de emergencia y requirieron sus servicios. Habiendo recibido las mismas explicaciones que la policía, el abogado respondió que "aunque la presencia de artesanos en la acera no viole ninguna norma, atenta contra la estética de la Avenida del Libertador", por tratarse de "cabecitas negras"16, "villeros", "delincuentes", "gente que ya se sabe cómo son ... lo mismo de la villa 3 1"17. $^{\prime \prime}$

Años atrás se había producido un acontecimiento de similares características, cuando se hizo instalar en la vereda un teléfono público que ofrecía información en varios idiomas sobre el museo. Una vecina se apersonó objetando que éste afectaba la estética de la avenida, por la posibilidad de que "el personal doméstico femenino de la zona utilice las cabinas para hablar con sus novios". Cousillas anota en su texto que el conflictivo teléfono no difería del modelo que la empresa concesionaria de la zona norte instala en toda el área, y que el mobiliario utilizado en la Exposición es similar al que utilizan en las veredas las confiterías frecuentadas, entre otros, por vecinos del barrio. Por otra parte muchos "cabecitas negras" se desempeñan cotidianamente en la zona, en la construcción de edificios, en la provisión y reparación de servicios públicos,
15. Sobre los fundamentos conceptuales y el encuadre institucional de estas actividades, véase COUSILLAS, 2003.

16."Negro","cabecita negra” son términos que en Argentina se utilizan para referir al mestizo, de piel parda o cetrina, cabellos morochos, ojos oscuros, aunque más allá del color u otras marcas visibles, usualmente aluden a una condición social baja. Esto se evidencia en expresiones como "negro de la cabeza", que dan cuenta de que no se trata de una cuestión de piel sino de clase social Es una categoría amplia que en su uso general refiere despectivamente a pobres, indígenas, criollos, provincianos, aunque en el medio familiar tiene, por el contrario, connotaciones afectuosas y positivas.

17.Se llama "villeros"a los habitantes de las villas "Villa" es una expresión apocopada de "villa miseria”, término localmente utilizado para designar los enclaves de mayor pobreza e indigencia de la ciudad, los que en otros países latinoamericanos se conocen como "pueblos jóvenes", "callampas", "cantegriles", "favelas", etc. La Villa 31 está en la zona de Retiro, próxima al centro y a Palermo Chico,separada de éste por parques, vías y playones de maniobra del ferrocarril.Se trata de una villa emblemática pues desde hace 30 años ha sido objeto de diversos planes tendientes a erradicarla de la zona, habida cuenta de su altísimo valor inmobiliario. 
18. Nótese que tanto Flores como Balbuena usualmente son apellidos, sin embargo a Ogwa se le impuso en sus documentos paraguayos el nombre Flores, el que por otra parte parecería ser femenino y no masculino.

19. Al respecto veáse CORDEU, 1989. en el cuidado de niños y en la realización de compras para los hogares en los que sirven. Como bien señala la autora,

lo que violenta y rompe las reglas de su noción sobre la estética de la Avenida, es que personas como éstas desempeñen roles que los coloquen en pie de igualdad en tanto usuarios de este espacio público con los vecinos, ya asumiendo el rol de productores culturales, ya como usuarios de un servicio público (COUSILLAS, 2001, p. 217).

Lo referido ilustra cómo algunos de los vecinos de Palermo Chico conciben a la Avenida del Libertador como un patrimonio propio y exclusivo, al que no deben tener acceso "los otros", pese a tratarse de un eje monumental, recreativo y cultural de la ciudad, lo que enfatiza su carácter de espacio público. Al reducir ese patrimonio a una "estética" en la que se atribuyen protagonismo excluyente, no sólo diluyen y banalizan su sentido, sino que desconocen en forma abierta los derechos de la ciudadanía. Por otra parte, no exploran disposiciones para reconocer el patrimonio, o mejor dicho, los patrimonios, de "los demás", y no confieren a las instituciones responsables legitimidad en la identificación y gestión del patrimonio cultural. Asimismo, se muestran incapaces de percibir distinciones entre los distintos tipos físicos de poblaciones diferentes entre sí, etiquetándolas bajo un rótulo común despectivo. De este modo convierten un evento de promoción del patrimonio cultural autóctono, en un hecho delictivo pasible de intervención policiaco-judicial. Todo ello se nutre de estereotipos, estigmatizaciones, prejuicios, racismo y discriminación, que en el caso particular de los pueblos indígenas, encuentran amplio sustento en los contenidos de la formación cívica e histórica provista por las prácticas educativas del Estado nacional. El dicho "los argentinos descendemos de los barcos" reitera desde el sentido común lo que la enseñanza pontifica acerca de que no existen indígenas en el país, que a lo sumo son un recuerdo del pasado remoto, y que somos descendientes de inmigrantes europeos. Nociones similares a éstas, no tanto por el contenido concreto como por su rechazo de las poblaciones indígenas, se encuentran en distintos sectores de la población, inclusive en aquellos mejor dispuestos hacia la alteridad. También puede reconocérselas en otros países latinoamericanos, con diversos matices acordes a las situaciones nacionales. Al respecto resulta ilustrativa otra situación planteada en relación con el Museo Hernández.

En octubre de 2002, en ocasión de realizarse la III Exposición y Feria Artesanal Cultural de los Pueblos Originarios, expuso sus obras en el Museo José Hernández el artista plástico chamacoco Ogwa, identificado por el Estado paraguayo como Flores Balbuena ${ }^{18}$. Tomamos contacto personal con él a través de Edgardo Cordeu, quien lo conoce desde que en los años 70 emprendió sus investigaciones etnológicas con los chamacoco o ishir del Chaco Boreal ${ }^{19}$. Este pueblo vio derrumbarse su modo de vida a medida que las industrias extractivas, los misioneros y los Estados nacionales ocuparon la región, y sus territorios ancestrales fueron usurpados y cercados. Ogwa nació en Bahía Negra, cerca de la triple frontera entre Paraguay, Brasil y Bolivia, fue iniciado siguiendo los ritos tradicionales a los 12 años, y llevó una vida trashumante hasta que, según 
él mismo relata, la etnóloga Bratislava Susnik lo "sacó del monte" en los años 50'. Ella fue quien por primera vez le proveyó materiales, y lo incitó a dibujar y pintar diversas escenas de su cultura expresadas en los mitos y rituales nativos, lo que desde los 70' continuó haciendo con Edgardo Cordev²0. Paralelamente, entre 1959 y 1969, fue traductor de la Biblia para la Misión Evangélica Nuevas Tribus, y adquirió un fluido manejo del español y del guaraní que se une a su conocimiento de las lenguas caduveo, quechua y aymara. Más tarde, se instaló en las afueras de Asunción, donde continuó desarrollando su labor artística, ilustró libros, expuso en galerías y recibió premios por su obra ${ }^{21}$, que ha llegado a comercializarse en España, Francia, Suecia y Canadá. Con todo, Ogwa jamás cesó de trasladarse con mucha frecuencia hacia Bahía Negra y las zonas frecuentadas por los chamacoco en Brasil y Bolivia. Una pequeña "tarjeta de trashumante" donde se atestigua su condición de indígena, firmada por un juez de paz paraguayo y protegida por un plastificado, hace las veces de pasaporte y "legaliza" sus desplazamientos por las tierras tradicionales, hoy divididas por las fronteras de tres Estados nacionales ${ }^{22}$.

En el dominio que en occidente denominamos "arte", o más precisamente "arte étnico", los ishir practicaban una ornamentación abstracta y geometrizante, ostensible en el tejido y la cestería. La pintura corporal que, aludiendo a su dualismo cosmológico, recubría partes enteras del cuerpo con los colores rojo y negro, junto con el blanco ${ }^{23}$, se realizaba en fajas alternas y combinadas geométricamente, sobre las que se imprimían manos, líneas, puntos, anillos, escamas y diseños ramificados. La cerámica y la talla en madera, caracterizada por sus motivos zoomórficos y figurativos, son producto de influencias tardías de mbayá caduveo y misioneros, que no guardan relación con el complejo mítico ritual sino con el intercambio comercial. En contraste con las pautas tradicionales, Ogwa realiza un trabajo de tipo figurativo, con dibujos realizados en lápiz, tinta o birome y pintados con témpera, lápices de colores y sellados. Hombres dioses que bailan en el éxtasis ritual, delgadas palmeras agitadas por el viento, pájaros, chanchos del monte, avestruces y víboras ocupan, junto con las escenas mítico rituales, el centro de sus preocupaciones pictóricas y de su memoria cultural.

Sus figuras se recortan sobre fondos donde se percibe la frondosidad del paisaje y el cielo chaqueño, y todas sus obras llevan una leyenda escrita que sitúa al espectador en la escena representada. Ello da cuenta de la familiaridad del autor con el mito, a la vez que de su distancia con él, esto es, del alejamiento producido en esa trayectoria bisagra entre los dos mundos sobre los que transita su vida. La obra de Ogwa no se ciñe a la recuperación de un pasado cultural idílico, sino que constituye una mirada actual de la historia de los chamacoco, que se nutre del dinamismo y la complejidad de la relación intercultural. Su obra es más que un intento por descubrir el velo de la memoria de una sociedad, cuyo proceso de confinamiento y desestructuración, no ha alcanzado a borrar las huellas de un pasado que se resiste a transigir. Es también una expresión de quienes se niegan a ser interpretados como meros testimonios de un presente etnográfico ajeno al devenir histórico, mostrándonos cómo la
20. Hemos realizado un trabajo más extenso sobre este tema en coautoría con Ana M. Spadafora. Un resumen del mismo se halla publicado en BAYARDO; SPADAFORA, 2003.

21. Es interesante anotar que en 1995, Ogwa recibió el Premio Ignacio Nuñez Soler "al arte naif" en el Bosque de los Artistas (de Asunción del Paraguay), extendido a nombre de Flores Balbuena. Tanto esto último como la categoría premiada muestran las dificultades desde la sociedad nacional paraguaya para reconocer su condición étnica.

22. Un tratamiento más exhaustivo de este tema puede verse en SPADAFORA, 2003.

23. Estos colores se obtenían de sustancias naturales como la hematita, el hollín, las cenizas y el caolín. 
24. En julio de 2002 tuvo lugar en Buenos Aires la $11^{\circ}$ edición de la feria de galerías de arte Arte BA que a diferencia de las anteriores dio lugar a espacios y a artistas emergentes. Ello se debió al estallido de la crisis que a fines de 2001 terminó con la paridad peso / dólar en el país (llevando la cotización a $\$ 3,50$ por dólar) y con el cese de los pagos de la deuda externa. Como consecuencia, la feria se abrió a otras expresiones, jóvenes, nacionales, con precios accesibles y en pesos, en detrimento de los artistas consagrados y/o con precios en dólares. Los artistas jóvenes vendieron sus obras entre \$400 y \$ 2.500 (aproximadamente entre U\$S 115 y U\$S 715).Véase "Con mucho público y buenas ventas finaliza hoy Arte BA" nota de Maricruz Barcia en el diario La Nación, Buenos Aires, 21/7/2002 recuperación de la memoria es un modo de situarse en el presente y perfilar el futuro.

Son estos aspectos significativos de la pintura de Ogwa y la calidad de su factura, las que llevaron a las autoridades del museo a distinguir sus obras como un trabajo más artístico que artesanal, que ameritaba condiciones de exhibición distintas que las del conjunto de la III Exposición y Feria Artesanal Cultural de los Pueblos Originarios. Es por ello que sus pinturas se exhibieron enmarcadas en parte del subsuelo del museo. Dado que, como dijimos, el museo por cuestiones administrativo financieras no puede realizar ventas, estas operaciones las canalizó la Exposición y Feria con apoyo de una Organización No Gubernamental. Es interesante marcar este contraste entre la pintura exhibida como arte y la obra vendida como artesanía, pues llama la atención sobre esas distinciones. No queremos aquí volver sobre un debate teórico no zanjado, pero sí anotar la jerarquización implícita en la clasificación arte/arte popular/ artesanía, y en las connotaciones que esto tiene con respecto al valor de cambio de la obra, pues es claro que éste disminuye en la medida que nos acercamos a la artesanía. De todos modos, en este caso ésa era la única manera en que las pinturas podían ser comercializadas.

La treintena de trabajos que Ogwa trajo para la venta, se vendieron cada uno en diez dólares (U\$S 10,00) y prácticamente se agotaron en el primer día de la Exposición y Feria. Los compradores fueron personas que respondieron a la invitación del Museo y de la ONG para participar de la apertura del evento. Se trataba fundamentalmente de personas allegadas a ambas instituciones, familiares y amigos, pero también de antropólogos, de estudiantes y de coleccionistas de arte. A partir de los diálogos que mantuvimos en esa ocasión, reconstruimos dos tipos de motivaciones que se hicieron explícitas a la hora de valorar y/o adquirir las obras. El primer tipo de motivaciones se afirmaba en los aspectos artísticos o estéticos, incluyendo dos vertientes diferenciadas. Una más ligada a antropólogos, coleccionistas y "conocedores", refería al valor estético de la pintura, destacando su condición de arte "indígena". La otra, provenía de un público menos familiarizado que, con mirada occidental, hacía una identificación de las obras con el estilo artístico conocido como naif o ingenuo. El segundo tipo de motivación, estaba presente en muchos de los asistentes, entremezclado sin antagonismo con los anteriores, y apuntaba a poner en práctica una acción de "solidaridad con el indígena". Esto último resultaba algo esperable, porque el evento era propiciado por la ONG en cuestión, y por el mismo perfil de los visitantes. Pero por otra parte, muestra que el peso relativo concedido a la condición de indígena puede estar oscureciendo o dando un reconocimiento parcial a la condición de artista, como si ambas cosas no pudieran terminar de conjugarse aún en personas abiertas a la alteridad.

Cabe consignar que el precio de diez dólares era una cifra superior a la que Ogwa podía obtener vendiendo una pintura en las calles de Asunción, como hace habitualmente. Pero por otro lado, en Buenos Aires si bien se trataba de un monto aceptable para una artesanía, resultaba muy bajo para una obra artística $^{24}$. Más exiguo aún si se toma en consideración el funcionamiento del 
mercado internacional de este tipo de obras. Así un antropólogo norteamericano, coleccionista de arte nativo australiano, comentaba que esas piezas usualmente se vendían entre los quinientos (U\$S 500,00) y los cinco mil dólares (U\$S 5.000). Y agregaba asombrado que en el caso de Ogwa, tratándose de una producción original y muy en las márgenes del mercado de arte, el valor debía ser superior, pues la obra de arte étnico marcada por las huellas del mercado, disminuye su precio. El caso australiano puede estar refiriendo a una situación nacional incomparable con ésta, pero resulta de importancia porque es una señal más de lo poco que se pagó por la obra de Ogwa, pese a que el Museo la consideró especialmente. En términos generales muestra que el valor de cambio del "arte étnico" en sintonía con el cultural-capitalismo pasa más por el exotismo y por la diferencia que por la ponderación de la obra en relación al artista, su trayectoria y su reconocimiento. La cotización de la obra, en contraste con lo usual en el arte sin adjetivos, aparece escindida de su creador, y el artista, por el hecho de ser indígena, no alcanza a ser reconocido plenamente. Nótese que como señala WILLIAMS (1997) buena parte de los artistas consagrados por el modernismo eran migrantes y en ese sentido también eran "extraños", pero al serlo en tanto ciudadanos de otros Estados nacionales pudieron transitar caminos de reconocimiento, circunstancia que en el caso de Ogwa presenta otras aristas.

Gestión cultural y políticas culturales transversales

Los Estados nacionales latinoamericanos se constituyeron en el siglo diecinueve sobreimponiéndose a los pueblos originarios que tradicionalmente vivían en los territorios que éstos ocuparon. Sus tendencias uniformizantes plasmaron en la negación de estas sociedades, por la vía del etnocidio lla conversión al cristianismo, la enseñanza del castellano, el servicio militar obligatorio, la ruptura de sus modos de vida), cuando no del genocidio (persecuciones, matanzas, campañas militares, cercamiento y privación de sus fuentes de subsistencia). Este proceso de negación persiste actualmente mediante diversas prácticas: la folklorización y espectacularización de los modos de vida nativos, el no reconocimiento pleno de las lenguas indígenas, los nombres propios y las diversas identidades étnicas, las dificultades interpuestas a la educación bilingüe, a la restitución de territorios y a la circulación entre Estados, los abusos ejercidos por las mismas autoridades ${ }^{25}$. Con la globalización ha habido avances en este campo, en ocasiones apenas por una retórica comercial de la diversidad cultural al estilo Benetton ${ }^{26}$, en otros casos mediante acuerdos que, como el Convenio 169/1989 de la OlT, comienzan a dejar su impronta en las Constituciones Nacionales. Pero esta misma situación da cuenta de una continuidad de derechos no efectivizados, y de una negación de la ciudadanía que no conocieron los artistas del modernismo europeo.

El caso de Ogwa se inscribe con el de otros indígenas que los Estados de esta parte del mundo continúan procurando ignorar, y por ello sus posibilidades
25. Ogwa relata que en los pasos fronterizos es usual que le quiten parte de las tallas en madera y de los trabajos en plumaria que traslada, aduciendo que pueden transmitir plagas.

26. Es interesante señalar que esta empresa textil y de indumentaria, que posee extensos campos en la patagonia argentina, se ha mostrado como uno de los principales enemigos de la población mapuche que allí vive, disputándole sus tierras con la connivencia de los poderes locales. 
27. Las identidades, siguiendo a Maura Penna (1992, p. 81-82, n/traducción), son "formas de re conocimiento que involucran disputas en torno de criterios de delimitación y cualificación de grupos (esquemas clasificatorios y sus atributos) o de la pertenencia de un individuo a él,y que se encuentran en movimiento tanto a partir del interior del grupo (o individuo) en cuestión como a partir de otros grupos que le son exteriores, o sea, de la sociedad". La autora denomina auto-atribución (autoadscripción) o identidad pretendida a los criterios interiores al grupo, y alter-atribución o identidad reconocida a los provenientes de otros grupos sociales. Considera que las disputas o luchas por el reconocimiento procuran desde el endogrupo hacer coincidir la identidad pretendida con la reconocida. de sobrevida pasan por amoldarse a las oscilaciones entre la venta en las calles locales y la venta para coleccionistas cosmopolitas, entre la exhibición como arte en el museo y la venta como artesanía en la feria. Algo similar ocurre con su identidad ${ }^{27}$, definida entre la autoadscripción como ishir y la denominación externa como chamacoco, entre el aborigen Ogwa y el paraguayo Flores Balbuena, entre el artista y el indígena, entre el artista étnico y el artista naif, entre el artista y el artesano, entre la valoración estética de su obra y la valoración ética de la solidaridad. En este sentido es interesante señalar que por el contra de las atribuciones de "primitivismo", "atavismo", "fundamentalismo", "cristalización", con las que se ha pretendido vincular indisolublemente a lo local y lo tradicional, con Ogwa nos encontramos ante la conformación de una identidad compleja y dinámica, multilingue, signada por las relaciones con otros pueblos indígenas y con otros blancos pertenecientes a distintas sociedades nacionales, y por el esfuerzo de reformular su propio mundo acorde a las nuevas circunstancias de la vida.

Desde esta perspectiva llama aún más la atención la defensa de la estética de la Avenida del Libertador realizada por algunos vecinos de Palermo Chico, a los que nos hemos referido. Si Buenos Aires es una capital que se precia de ser cosmopolita, este sector más que ninguno en la ciudad tiene acceso a las nuevas tecnologías de la información y la comunicación, los viajes en avión, la interacción con personas de otras culturas, lenguas o religiones, el uso de vestimentas y accesorios adquiridos en free shops y en las capitales internacionales de la moda. Pero los hijos selectos de la modernidad y el cosmopolitismo se comportan con virulencia premoderna en defensa de una identidad local acrisolada en torno a "su" patrimonio. Este último sólo es tal en tanto resulta desgajado del espacio público, apropiado y negado al otro, en una negación que no refiere al desconocimiento de la alteridad, sino de la igualdad de derechos presupuesta en la ciudadanía. En este caso nos encontramos ante la constitución de una identidad local cristalizada, que no se contrapone al mercado transnacional ni puede ser explicada como una reacción de defensa ante la globalización.

Indudablemente las identidades locales distan de adecuarse a los estereotipos que circulan acerca de ellas, tráteselas en términos de "atavismos" o de "reacciones autodefensivas". Su conformación es resultado de elaboraciones más complejas y variadas en las que lo local y lo global se constituyen mutuamente, acorde a circunstancias concretas y no a una dinámica universal. Así se hace imposible predeterminar quienes son los cosmopolitas y quienes los locales, y qué aspectos de la globalidad y la localidad resultarán relevantes en las actualizaciones identitarias que reorganizan las clasificaciones, representaciones y jerarquías del orden social. Proponiéndoselo o no, los museos intervienen en estos procesos y en la conflictividad social que vehiculizan. Por ello este problema es parte de la gestión de los museos y cada institución debe encararlo acorde a sus circunstancias particulares. Pero los esfuerzos aislados de las mejores instituciones no bastan para desarticular las exclusiones que las mismas estructuras del Estado han contribuido a establecer y naturalizar. Y ello es así porque nos 
desenvolvemos en un espacio público cuyas coordenadas se definen más ampliamente que en el seno de las instituciones y de las interacciones inmediatas.

En tal sentido también se hace necesario reflexionar sobre las articulaciones entre Estado, mercado y comunidad que anotábamos más arriba. En este nuevo contrato social los museos supuestamente deberían hallar su anclaje en alternativas que implican nuevas formas institucionales (cómo la transformación en sociedades del Estado, la vinculación con fundaciones, o el establecimiento de encuadres mixtos entre público y privadol y nuevas relaciones con sus visitantes (como la apertura a la multiplicidad de públicos, la amigabilidad de sus instalaciones y sus pautas de funcionamiento ${ }^{28}$. Y esta flexibilidad le permitiría hallar a cada museo su medio cultural, sus públicos, su sostenibilidad, y llevar a cabo del mejor modo posible su misión.

El caso del Museo de Arte Popular nos lleva a pensar que ésta es una visión parcial del problema. Como ya se dijo, en el marco de los ajustes y recortes presupuestarios, los museos apenas pueden mantener las infraestructuras, los equipamientos, las colecciones y los salarios de su personal. En aras de su sostenibilidad desde el mismo Estado se les alienta a buscar otras fuentes financieras. Pero inclusive con el recurso a las asociaciones de amigos y a los acuerdos con entidades privadas y comunitarias, escasamente se logra solventar los gastos operativos. El ámbito público propone, pero el que en definitiva dispone es el mercado, y esta decisión de la "mano invisible" no asegura la visibilidad ni la diversidad deseables de expresiones y de actores. Así, los artesanos indígenas que exponen en la Exposición y Feria a que nos venimos refiriendo son sólo aquellos que pueden pagarse el viaje hasta Buenos Aires y la estadía en la ciudad. A esto debe agregarse que las construcciones patrimoniales y los conflictos identitarios sobre los que el museo procura trabajar con una propuesta superadora no solo se hallan en el pasado de la institución, también están arraigadas en numerosos aspectos de la sociedad contemporánea. En tal sentido se hace necesaria una intervención integral y reflexiva que requiere de diagnósticos previos, acciones programadas para el largo plazo, y un seguimiento de las mismas que de lugar a reformulaciones del rumbo trazado.

La institución aislada encuentra serios obstáculos para tal tipo de accionar en un medio que es resultado de estructuras e interacciones más vastas, y de una cultura pública que la excede en tanto es resultado de múltiples determinaciones. Con todas sus limitaciones, el agente que más opera en procura del interés general ha sido tradicionalmente el Estado en sus distintos niveles. Consecuentemente, por contra de la búsqueda de soluciones por la vía del interminable achicamiento del Estado al que asistimos en Latinoamérica (que no ha hecho más que empeorar las cosas), más bien hace falta más Estado y muy concretamente políticas culturales que vayan más allá de la gestión cultural localizada en una institución e inclusive en el mero sector cultural. Es necesario elaborar e implementar políticas relativas a la educación y a la comunicación, políticas lingüísticas y políticas con respecto a las migraciones, sin excluir otros ámbitos como la salud, la vivienda, el deporte, etc., pues las políticas culturales para ser efectivas no pueden quedar limitadas a una problemática sectorial, sino 
que deben atravesar y vincular la dimensión cultural de las distintas áreas de la vida social.

En el contexto de los mercados transnacionales, tales políticas culturales no necesariamente han de conformarse contra la mencionada economización del sector de la cultura, sino que más bien han de incluirla en su agenda. Esta debe ser reconocida como un proceso no sólo definido por las presiones de las grandes corporaciones del cultural-capitalismo, sino también por las activaciones patrimoniales e identitarias de actores de distintos sectores, muchos de ellos subprivilegiados, que buscan mejores posicionamientos materiales y simbólicos en un paisaje de acechante exclusión social. El desafío de estas políticas es superar las propuestas balsámicas y conformistas de la engañosa inclusión cultural. Ésta hace un elogio estetizante y desleído de la diversidad cultural, que niega sus condiciones efectivas e invisibiliza desigualdades y conflictos. Por ello no contribuye a conformar una ciudadanía que involucre el reconocimiento pleno de los derechos civiles, políticos, sociales, económicos y culturales de todos. De aquí que en las políticas culturales, la complejidad de las intervenciones en pro de la integración social debe anteponerse a la celebración del multiculturalismo feliz.

\section{REFERENCIAS}

APPADURAI, A. Disjunção e diferença na economia cultural global. In: FEATHERSTONE, M. (Org.). Cultura global. Nacionalismo, globalização e modernidade. Petrópolis: Editora Vozes, 1994.

BAYARDO, R. Cultura, artes y gestión cultural. La profesionalización de la gestión cultural. In: III JORNADAS DE INVESTIGACIÓN DEL INSTITUTO DE HISTORIA DEL ARTE ARGENTINO Y LATINOAMERICANO, FFyL, UBA, 2001 (www.leedor.com/sociedad/gestioncultural.shtml).

BAYARDO R.; LACARRIEU, M. Globalización e identidad cultural. Buenos Aires: Ediciones Ciccus, 1997.

La dinámica global local. Cultura y comunicación: nuevos desafíos. Buenos Aires: Ediciones Ciccus - La Crujía, 1999.

BAYARDO, R.; SPADAFORA,A. M. Ogwa: pintar el pasado para reinventar el futuro. Aproximaciones al arte de los chamacoco o ishir del Chaco Boreal Paraguayo. Resumen. In:A.A.V.V. Discutir el canon. Tradiciones y valores en crisis. Buenos Aires: CAIA, 2003.

BIALOGORSKI, M; COUSILLAS,A. M. Gestión cultural y estudios de público en el Museo Hernández de la ciudad de Buenos Aires. Cuadernos de Antropología Social, Buenos Aires, n. 12, p. 195-205, 2000.

CANCLINI, N. G. (Ed.). Políticas culturales en América Latina. México: Grijalbo, 1987. . La globalización imaginada. Buenos Aires: Editorial Paidós, 1999. 
CORDEU, E. J. Los chamacoco o ishir del chaco boreal. Algunos aspectos de un proceso de desestructuración étnica. América Indígena, v. XLIX, n. 3, jul.-sep, 1989.

COUSILLAS, A. M. Sobre patrimonio cultural, imaginarios y conflictos. In: A.A.V.V. Temas de patrimonio 5, primeras jornadas de patrimonio intangible "Memorias, identidades $e$ imaginarios sociales”. Buenos Aires: Comisión para la Preservación del Patrimonio Histórico Cultural de la Ciudad de Buenos Aires, 2001.

Reflexiones desde la gestión sobre el patrimonio cultural artesanal en un museo de la ciudad de Buenos Aires. In: PRIMER CONGRESO UNIVERSITARIO DE FOLKLORE, Universidad Nacional de Córdoba, 20 al 23 de junio de 2003.

CUICUILCO, N. E. Nueva museología mexicana. México, México D. F., v.3, n. 7, may.- ago. 1996.

ENZENSBERGER, H. M. Crítica de la ecología política. Buenos Aires:Amorrortu Ediciones, 1987.

FONDO NACIONAL DE LAS ARTES - FUNDACION ANTORCHAS. Lo público y lo privado en la gestión de museos. Alternativas institucionales para la gestión de museos. Buenos Aires: Fondo de Cultura Económica, 1999.

GENTILI, P. El consenso de Washington y la crisis de la educación en América Latina. In:ALVAREZURÍA, F. et al (Comp.). Neoliberalismo versus democracia. Madrid: La Piqueta, 1998.

GETINO, O. Las industrias culturales en Argentina. Dimensión económica y políticas públicas. Buenos Aires: Colihue, 1995.

HARVEY, D. The condition of postmodernity. An enquiry into the origins of cultural change. Cambridge, USA; Oxford, UK: Blackwell Publishers, 1995.

HIRSCH, J. Interpretaciones de la interrelación entre capital, estado y mercado mundial desde la teoría de la regulación. In: HOLLOWAY, J. et. al. Globalización y Estados-nación. Buenos Aires: Editorial Homo Sapiens, 1995.

HUYSSEN,A. En busca del futuro perdido. Cultura y memoria en tiempos de globalización. México: Fondo de Cultura Económica, 2002.

JULIANO, D. Estrategias de elaboración de identidad. In: HIDALGO, C.;TAMAGNO, L. Etnicidad e identidad. Buenos Aires: Centro Editor de América Latina, 1992.

La construcción de la diferencia: los latinoamericanos. Papers, revista de la Universidad Autónoma de Barcelona, Barcelona, n. 43, p. 23-32, 1994.

LACOUTURE FORNELLI, F. La museología y la práctica del museo. Áreas de estudio. Cuicuilco, revista de la Escuela Nacional de Antropología e Historia, México D.F., Nueva Epoca, v. 3, n,7, p. 11-30, 1997.

MORALES MORENO, L. G. ¿Qué es un museo? Cuicuilco, revista de la Escuela Nacional de Antropología e Historia, México D.F., Nueva Epoca, v. 3, n. 7, p. 59-104, 1997. 
ORTIZ, R. Otro territorio. Ensayos sobre el mundo contemporáneo. Buenos Aires: Editorial de la Universidad Nacional de Quilmes, 1996.

PENNA, M. O que faz ser nordestino. Identidades sociais, interesses e o 'escândalo' Erundina. São Paulo: Cortez Editora, 1992.

PRATS, L. L. Antropología y patrimonio. Barcelona:Ariel, 1997.

RIZZARDO, R. Identités et politiques culturelles. In:SAEZ,J.P.(Dir.).Identités, cultures et territoires. Paris: Desclée de Brouwer, 1995.

SCHMILCHUK, G. Venturas y desventuras de los estudios de público. Cuicuilco, revista de la Escuela Nacional de Antropología e Historia, México D.F., Nueva Epoca, v. 3, n. 7, p. 31-57, 1997.

SONNTAG, H.; ARENAS, N. Lo global, lo local, lo híbrido.Aproximaciones a una discusión que comienza. In: PRIMERA REUNIÓN REGIONAL DEAMÉRICA LATINAY EL CARIBE DEL PROGRAMA GESTIÓN DE LAS TRANSFORMACIONES SOCIALES MOS-UNESCO, 28 al 31 de marzo, Buenos Aires, 1995.

SOSNOWSKI, S.Apuestas culturales al desarrollo integral deAmérica Latina.In:FORO DESARROLLO Y CULTURA BID - UNESCO, París, 11 y 12 de Marzo, 1999.

SPADAFORA, A. Tarjeta de trashumante. La deuda pendiente de la agenda del MERCOSUR. In: http://www.bioetica.org, 2003.

WILliAMS, R. La política del modernismo. Contra los nuevos conformistas. Buenos Aires: Manantial, 1997.

YUDICE, G. El recurso de la cultura. Usos de la cultura en la era global. Buenos Aires: Gedisa, 2002.

ZUKIN, S. The cultures of cities. Cambridge USA \& Oxford UK: Blackwell Publishers, 1996.

Artigo apresentado em 07/2005. Aprovado em 10/2005. 